\title{
New Results in Researching the Relationship between Light Trapping of Ostrinia nubilalis Hbn. and Some Features of Night Sky and the Moon in Hungary and USA
}

\section{Nowinszky L1*, Puskas J and Kiss M \\ ${ }^{1}$ Department of Zoology, Eotvos Lorand University, Hungary}

*Corresponding author: Laszlo Nowinszky, Eotvos Lorand University, Savaria Campus Savaria Science Centre, 9700 Szombathely Károlyi Gáspár Square 4, Hungary, Email: lnowinszky@gmail.com

\section{Research Article}

Volume 2 Issue 4

Received Date: July 03, 2019

Published Date: July 23, 2019

DOI: $10.23880 /$ izab- 16000168

\section{Abstract}

This paper treads with the certain features of night sky and the Moon in connection with the success of light trap catch of European Corn-borer (Ostrinia nubilalis Hübner, 1790) in Hungary and Nebraska and North Carolina states of USA between 1959-2006 and 1994-2017.

The features were examined as follows: altitude of the Sun's Arago point above horizon, altitude of the Moon's Babinet point above horizon, altitude of the Moon above horizon, apparent magnitude of the Moon, illuminated fraction of the Moon and the moonlight.

Calculations were made between these factors and the catch data. The results were depicted together with the confidence intervals.

We have found that the neutral points of the sky and the features of the Moon that have not yet been investigated. A similar effect can be seen in the results of the light-trap catch of the Ostrinia nubilalis Hbn. both in Hungary and in America.

Keywords: Moon's Features; Arago and Babinet Points; Light-Trap; European Corn-Borer; Hungary; USA

\section{Introduction}

Light trapping is a widespread method to investigate the activity of nocturnal insects. The effectiveness of light trapping as an insect sampling method was influenced by many environmental factors (for example astronomical, geophysical and weather effects). A lot of studies in the literature are devoted to the role of the Moon in modifying light-trapping catch. We mention some of them, not to strive for completeness.

Verkhovskaya [1] announced the first time that arthropods (Arthropoda) are able to distinguish between polarized- and not polarized lights. The entomologists, however, noticed so far on daytime active insects or at dusk. 


\section{International Journal of Zoology and Animal Biology}

The attraction of night flying insects to the polarized moonlight was examined by Hungarian entomologists. Nowinszky, et al. [2,3] found that some night flying beetles (Coleoptera), bugs (Heteroptera), caddisflies (Trichoptera) and moths (Lepidoptera) species are able use the Sun's and Moon's night sky polarization for their spatial orientation. Therefore, they fly in higher amount in the First- and Last Quarter to light than at New Moon or Full Moon. Dacke, et al. [4] conclude that the Moon is not a primary tool for orientation. The effective cue polarization pattern around the moon is more reliable for orientation. Dacke, et al. [5] wrote that the Bogong Moths (Agrotis infusa Boisduval) can use the polarized light pattern originated by Sun and the Moon and perhaps the Milky Way. The degree of polarization is maximal along a great circle of the sky being 90 degrees from the Sun, and minimal at the Sun and anti-Sun as well as at the Arago, Babinet and Brewster neutral points [6]. It was observed that several aquatic insects are liable to use the night sky polarization patterns [7]. Horváth has dealt with this topic in many studies with his colleagues [8-10]. It was examined the influence of the Sun's night sky polarization and gravitational potential on Macrolepidoptera individuals and species found the effect of Sun's night sky polarization on the light-trap catch of insects in Nebraska and North Carolina States [11]. It was established [12] different connection between the gravitation potential and night sky polarization of Sun and Moon and different group of insects (Coleoptera, Heteroptera, Trichoptera, Lepidoptera).

We have already published the influence of polarized moonlight and night sky polarization on light-trap catch European Corn-borer in both Hungary and the USA in our previous studies [13-16]. After these researches we thought to examine influences of several other factors (altitude of the Sun's Arago point; altitude of the Moon's Babinet point; altitude of the Moon; apparent magnitude of the Moon; illuminated fraction of the Moon; moonlight). These factors were not investigated earlier by researchers, so our results are totally new ones.

\section{Material}

The catching data of European Corn-borer (Ostrinia nubilalis Hübner, 1790, Lepidoptera: Crambidae) were taken from the light-trap registers of the Hungarian Lighttrap Network. During the years between 1959 and 2006. 321,795 months were caught by the 131 light-traps. Of course, not all light-traps operated all years, but some of them were ceased, others sited later. This many moths were trapping in 5,984 nights. However, because more light-trap worked during one night, we could work up 79,499 observation data.

The light traps of North Carolina and Nebraska supplied a huge scientific material over the past two decades for entomological basic research, and plant protection prognostics work for the farmers. In this investigation the BL traps data of USA States of North Carolina and Nebraska were used. These were downloaded from North Carolina Pest News on the Internet (http://ipm.ncsu.edu/currentjpm/pest_news.ht $\mathrm{ml}$ ) and the North Carolina Cooperative Extension Service (http://www.ces.ncsu.edu/) websites. The light-trap collecting data of Nebraska State were from the years 2000 and 2017 and the North Carolina State traps' material was found in years between 1994 and 2010. In these states, $15 \mathrm{~W}$ BL traps were in operation. The data collection was published several times each year for farmers, in order to utilize these data in their plant protection works. In North Carolina and Nebraska states were catching 88,223 moths by the 21 light-traps in 1,734 nights. We could investigate the 4,323 catching data.

The astronomical data were calculated with a program based on the algorithms and routines of the VSOP87D planetary theory for Solar System ephemeris and written in C by J. Kovács. The additional formatting of data tables and some further calculations were carried out using standard Unix and Linux math and text manipulating commands. We calculated the degree of the Sun'a Agaroand Moon's Babinet point for a geographic position of $46^{\circ}$ 54' 26.64"N and 19 41' 30.12"E (Kecskemét, Hungary)

\section{Methods}

We have calculated the relative catch values (RC) of the number of caught Ostrinia nubilalis $\mathrm{Hbn}$. species in Hungary and USA (North Carolina and Nebraska states). In order to compare the differing sampling data, relative values were calculated from the number of individuals and species for each sampling night per year. The RC was defined as the quotient of the number of specimen caught during a sampling time unit (1 night) per the average catch of individuals and species within the same aspect relating to the same time unit. For example, when the actual catch was equal to the average individual number captured in the same aspect, the RC was 1 [17]. The relative catch data was classified into the appropriate features. Features and the corresponding catch data were organized into classes. Their number was determined according to Sturges' method [18] using the following formula: $\mathrm{k}=1+3.3^{*} 1 \mathrm{gn}$ 
Where: $\mathrm{k}=$ the number of divisions, $\mathrm{n}=$ the number of observation data.

We depicted the results coming from the different features and the connection with light-trap catch. Figures also show the confidence intervals.

\section{Results and Discussion}

The results of our calculations are shown in Figures that illustrate the relationship between sky and Moon features and light-trap catch results of the European Corn-borer in Hungary and USA (North Carolina and Nebraska states) (Figures 1-3).

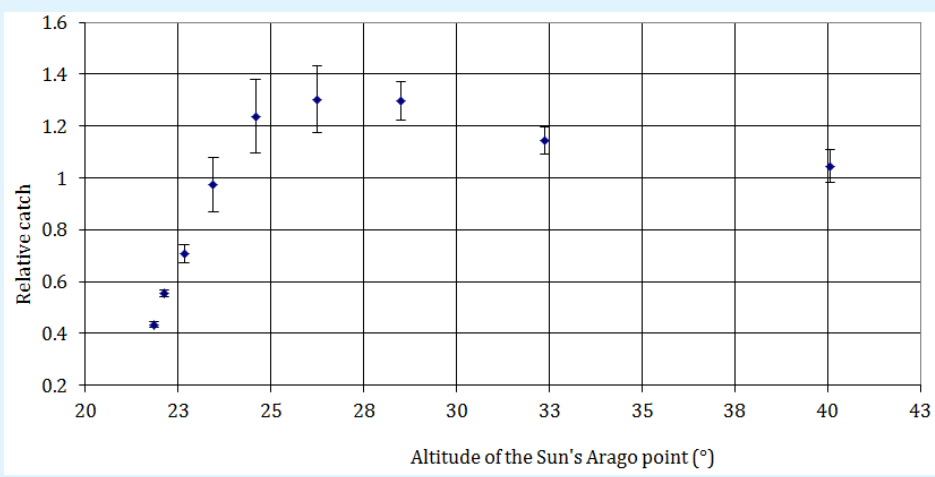

Figure 1: Light-trap catch of European Corn-borer (Ostrinia nubilalis Hübner) in connection with the altitude of the Sun's Arago point (North Carolina and Nebraska).

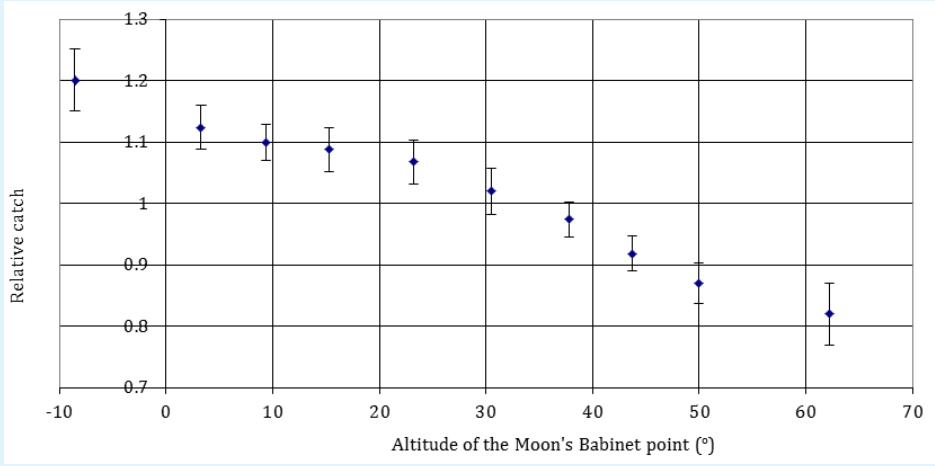

Figure 2: Light-trap catch of European Corn-borer (Ostrinia nubilalis Hübner) in connection with the altitude of the Moon's Babinet point (Hungary).

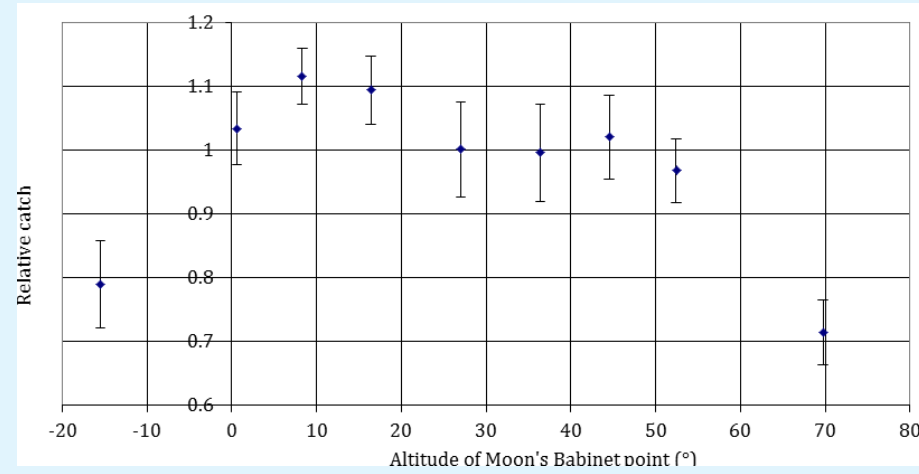

Figure 3: Light-trap catch of European Corn-borer (Ostrinia nubilalis Hübner) in connection with the altitude of the Moon's Babinet point (North Carolina and Nebraska). 
We could only determine the influence of the Sun's Arago point on the catch only from American data. The highest catch is at the height of the Arago point above 25 degrees, just at sunset. The catch is only slightly reduced until the Arago point is above the horizon. We did not get any measurable results with the Hungarian data.

The effect of the Moon's Babinet point is very similar in Hungary and in the USA. The highest catch is when it appears above the horizon, then decreases slightly. It seems to be proved that both the Sun's Arago point and the Moon's Babinet point provides more reliable orientation information for insects than the Moon, because the Moon is not above the horizon in the surroundings of the new moon and at some hours of the night.

The illumination created by the Moon changes not only on each night of the moon month and also during their night hours. In addition, we are experiencing similarities in the Moon's 18.6 years' motion of the Moon's nodes (Figures 4 \& 5).

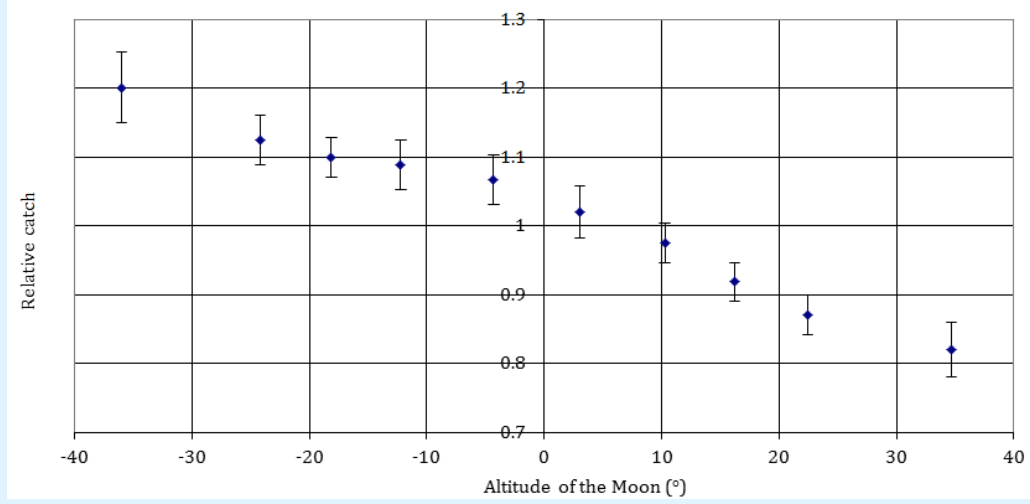

Figure 4: Light-trap catch of European Corn-borer (Ostrinia nubilalis Hübner) in connection with the altitude of the Moon (Hungary).

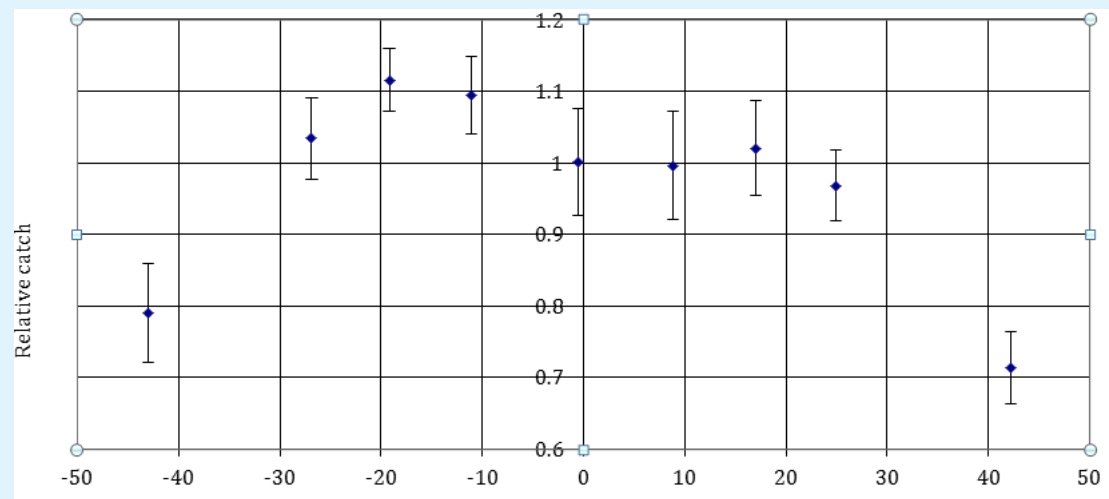

Figure 5: Light-trap catch of European Corn-borer (Ostrinia nubilalis Hübner) in connection with the altitude of the Moon (North Carolina and Nebraska).

The height of the Moon above the horizon, its visible brightness and its lit proportion also shows strong fluctuation in the different phases of the Moon. Therefore, they have very significant catch results, but they can only be considered statistical averages.
The effectiveness of the catch contrasts with the height above the Moon horizon, both in Hungary and in the USA. The highest catch is near the Moon horizon. 
The visible luminosity of the Moon is -12.74 magnitudes at the time of moonshine. The catch is low at this value. This result is the same as in all our previous studies [19].
The illuminated portion of the Moon, as well as the influence of moonlight on the catch, is clear and confirms the low catch around moonshine (Figures $6 \& 7$ ).

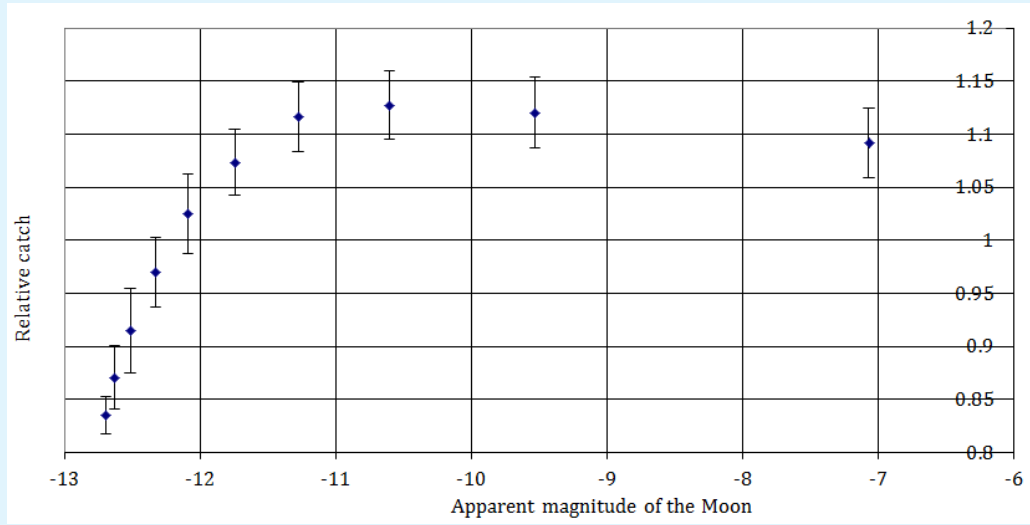

Figure 6: Light-trap catch of European Corn-borer (Ostrinia nubilalis Hübner) in connection with the apparent magnitude of the Moon (Hungary).

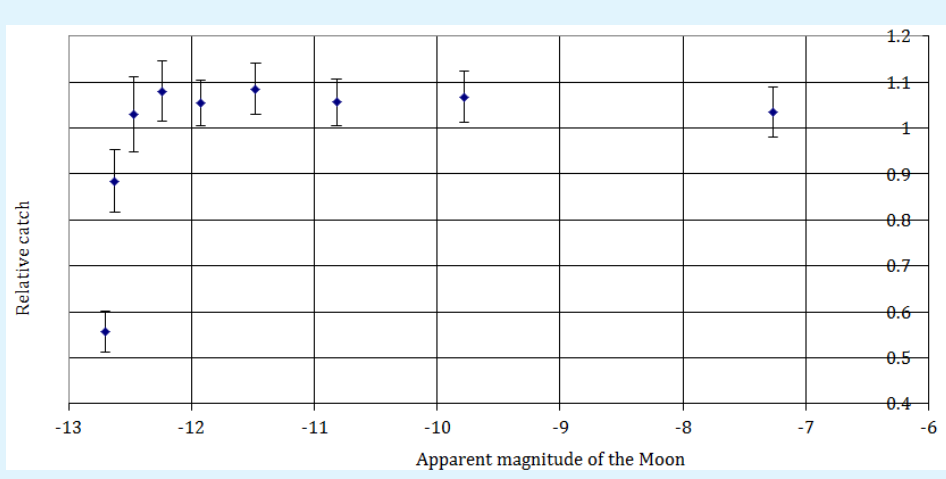

Figure 7: Light-trap catch of European Corn-borer (Ostrinia nubilalis Hübner) in connection with the apparent magnitude of the Moon (North Carolina and Nebraska).

We have to take into consideration two neutral points in the night sky, which is virtually zero in the polarization. These are the Sun's Arago point and the Moon's Babinet point. The Arago point follows the setting Sun at about 25 to 30 degrees. This is the same degree in case of the Moon's Babinet-point.

Insects can distinguish between polarized and nonpolarized light. Therefore, both neutral points can be seen as a continuity shortage. Both the Sun's Arago point and the Moon's Babinet point can help the spatial orientation of insects.

\section{Conclusions}

Our recent work calls attention of researchers to new influential environmental factors (Figures 8-11). These are the Sun's Arago point, the Moon's Babinet point, the altitude of the Moon, apparent magnitude of the Moon, illuminated fraction of the Moon and the moonlight. 


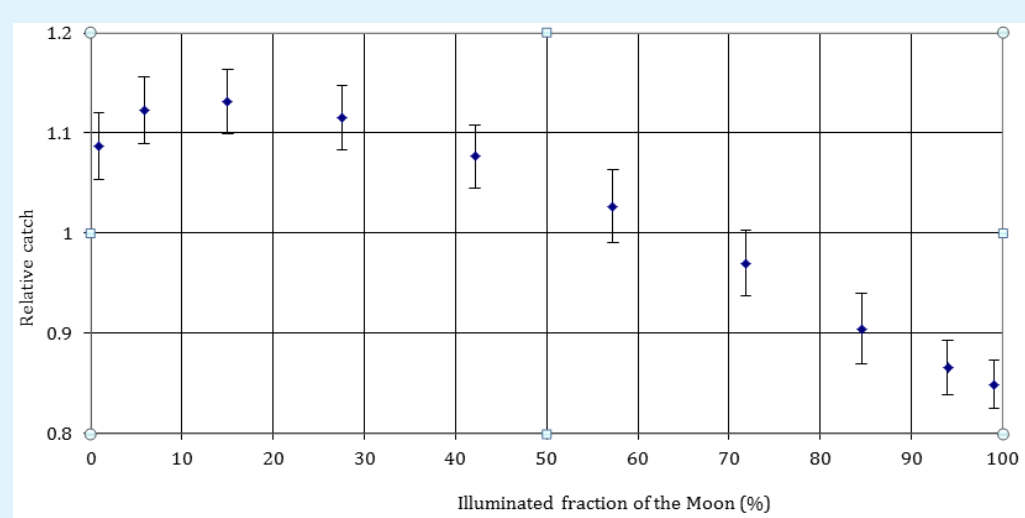

Figure 8: Light-trap catch of European Corn-borer (Ostrinia nubilalis Hübner) in connection with the illuminated fraction of the Moon (Hungary).

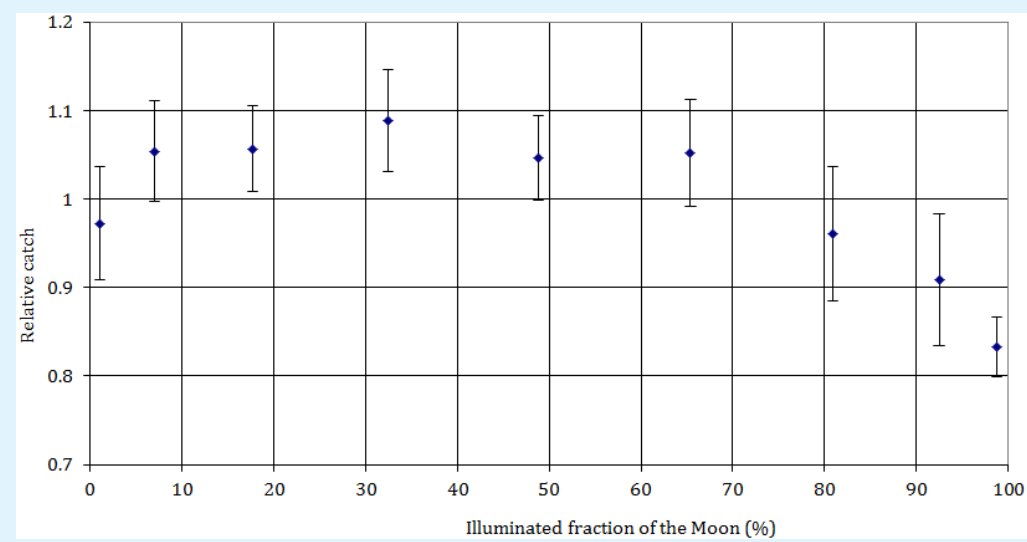

Figure 9: Light-trap catch of European Corn-borer (Ostrinia nubilalis Hübner) in connection with the illuminated fraction of the Moon (North Carolina and Nebraska).

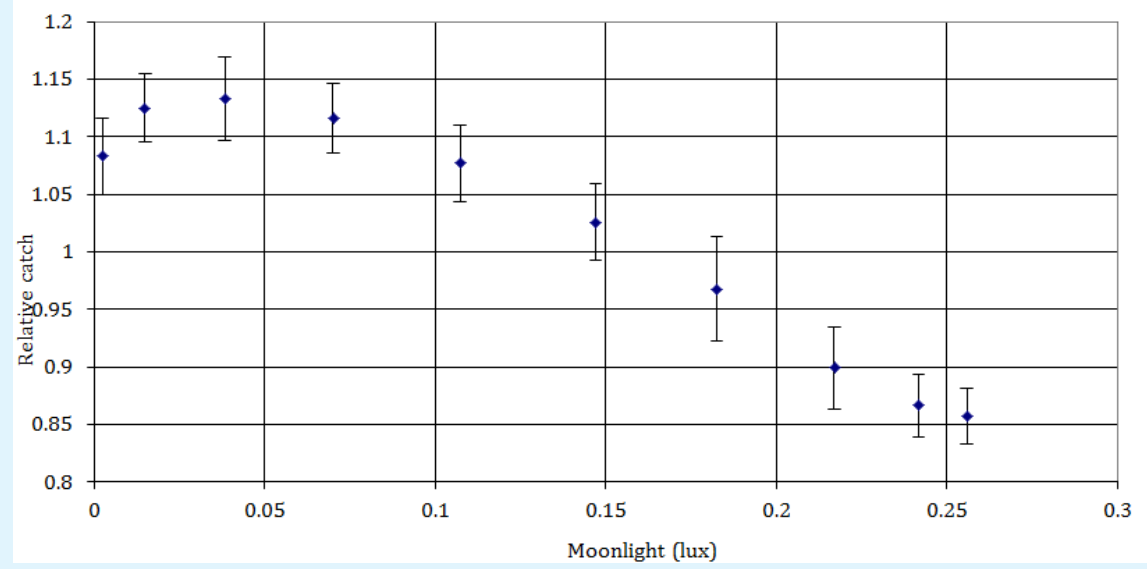

Figure 10: Light-trap catch of European Corn-borer (Ostrinia nubilalis Hübner) in connection with the moonlight (Hungary). 


\section{International Journal of Zoology and Animal Biology}

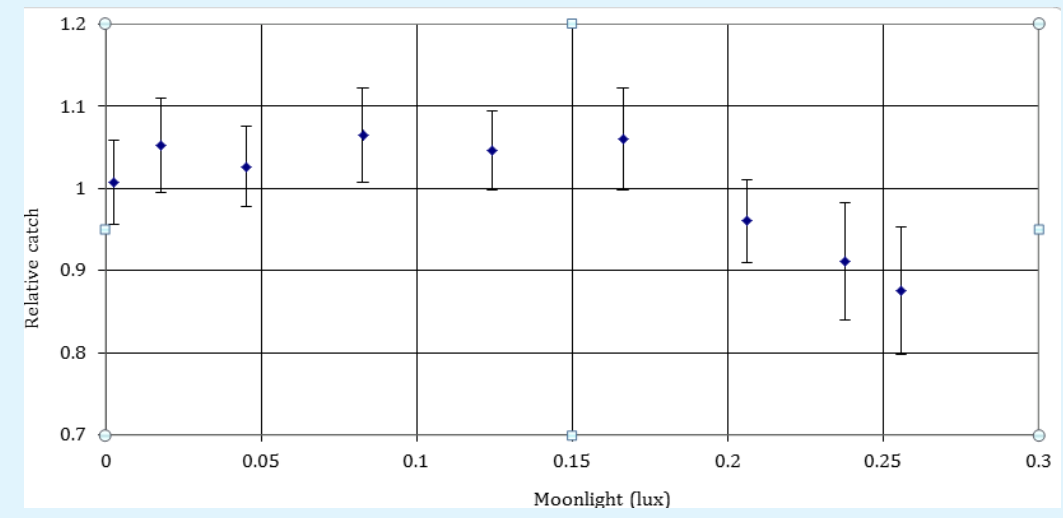

Figure 11: Light-trap catch of European Corn-borer (Ostrinia nubilalis Hübner) in connection with the moonlight (North Carolina and Nebraska).

\section{Acknowledgements}

We would like to thank J Kovács (ELTE Astrophysical Observatory, Szombathely) for calculating the Moon and Sun data and describing the method of investigation.

\section{References}

1. Verkhovskaya IN (1940) The influence of polarized light upon the phototaxis of certain organisms. Bull Nat Hist Soc Biol Section Moscow 49: 101-113.

2. Nowinszky L, Hirka A, Csoka GY, Petranyi G, Puskas J (2012) The influence of polarized moonlight and collecting distance on the catches of winter moth Operophthera brumata L. (Lepidoptera: Geometridae) by light-traps. Eur J Entomol 109: 29-34.

3. Nowinszky L, Kiss O, Szentkiralyi F, Puskas J, Ladanyi M (2012b) Influence of illumination and polarized moonlight on light-trap catch of caddis flies (Trichoptera). Res J Biol 2(3): 79-90.

4. Dacke M, Horvath G (2014) Polarized Light Orientation in Ball-Rolling Dung Beetles, Polarized Light and Polarization Vision in Animal Sciences, Springer Series in Vision Research pp: 27-39.

5. Dacke M, Baird E, Byrne M (2013) Dung beetles use the Milky Way for orientation. Curr Biol 23(4): 1-3.

6. Horvath G, Gal J, Pomozi I, Wehner R (1998) Polarization portrait of the Arago point: video polarimetric imaging of the neutral points of skylight polarization. Naturwiss 85(7): 333-339.
7. Horvath G, Varju (2004) Polarized light in animal vision. Springer Berlin Heidelberg pp: 447.

8. Sabbah S, Barta A, Gal J, Horvath G, Shashar N (2006) Experimental and theoretical study of skylight polarization transmitted through Snell's window of a flat water surface. J Opt Soc Am A Opt Image Sci Vis 23(8): 1978-1988.

9. Kriska Gy, Barta A, Suhai B, Bernath B, Horvath G (2008) Do brown pelicans mistake asphalt roads for water in deserts?. Acta Zool Acad Sci Hung 54 (S1): 157-165

10. Szaz D, Horvath G, Barta A, Robertson BA, Farkas A, et al. (2015) Lamp-Lit Bridges as Dual Light-Traps for the Night-Swarming Mayfly, Ephoron virgo: Interaction of Polarized and polarized Light Pollution. PLoS ONE 10 (3): e0121194.

11. Nowinszky L, Kiss M, Puskas, J, Barta A (2017) LightTrap Catch of Turnip Moth (Agrotis segetum Denis et Schiffermüller, 1775) in Connection with the Night Sky Polarization Phenomena. Glob J Res Rev 4(2): 22.

12. Nowinszky L, Kiss M, Puskas J (2018) Light-trap Catch of Microlepidoptera spec. indet. in Connection with the Gravitational Potential of Sun and Moon. Mol Ent 9(3): 29-34.

13. Nowinszky L, Puskas J (2009) Light-trap catch of European Corn Borer (Ostrinia nubilalis Hbn.) depending on the moonlight. Acta ent Serb 14(2): 163-174. 


\section{International Journal of Zoology and Animal Biology}

14. Nowinszky L, Puskas J (2012) Light-trap catch of the harmful moths depending on moonlight in North Carolina and Nebraska States of USA. Int Schol Res Network ISRN-Zoology pp: 6.

15. Nowinszky L, Puskas J (2015) Light-trap Catch of European Corn-borer (Ostrinia nubilalis Hübner) in Connection with the Polarized Moonlight and Geomagnetic H-Index. Ann Nat Sci 1(1): 3-8.

16. Nowinszky L, Kiss M, Puskas J, Barta A (2019) The Effect of Night Sky Polarization Originated by the Sun on the Light-Trap Catch of Insects in Nebraska and North Carolina States (USA). Mod Appl Bioequival Bioavailabil 4(2): 1-5.

17. Nowinszky L (2003) The Handbook of Light Tapping. Savaria University Press, Szombathely pp: 276.

18. Odor P, Igloi L (1987) An Introduction to the Sport's Biometry, ÁISH Tudományos Tanácsának Kiadása, Budapest pp: 267.

19. Nowinszky L (2008) Light Trapping and the Moon. Savaria University Press. Szombathely pp: 170. 